\title{
Computer-Mediated Communication Perspective on Theories of Mating Relationships: A Literature Review
}

\author{
Ayman BAJNAID ${ }^{1}$, Giuseppe Alessandro VELTRI ${ }^{2}$, Tariq ELYAS ${ }^{3}$ and \\ Ra'ed MASA'DEH ${ }^{4}$ \\ ${ }^{1}$ New Media and Communication, Faculty of Media and Communication, Communication Department, \\ King Abdulaziz University, Jeddah, Saudi Arabia \\ ${ }^{2}$ Research Methodology and Cognitive Sociology, Department of Sociology and Social Research, the \\ University of Trento \\ ${ }^{3}$ Applied Linguistics, European Languages Department, Faculty of Arts \& Humanities, King Abdulaziz \\ University, Jeddah, Saudi Arabia \\ ${ }^{4}$ Management Information Systems, School of Business, the University of Jordan
}

Received date: 11 March 2019; Accepted date: 27 April 2019; published date: 11 June 2019

Academic Editor: Fabrizio Amarilli

Copyright (C 2019. Ayman BAJNAID, Giuseppe Alessandro VELTRI, Tariq ELYAS and Ra'ed MASA'DEH . Distributed under Creative Commons CC-BY 4.0

\begin{abstract}
This study provides a review of the theories relevant to the understanding of online dating. Dating as a concept and as an activity has a specific history and takes a specific form. It traditionally occurred in the offline world although there were mediated aspects to it with daters advertising themselves in newspapers and magazines and on other available platforms. There are theories that try to explain the dating process and how relationships form between humans. There are associated theories of impression formation which are not exclusive to the dating context but are nonetheless relevant to it. There is then the migration of these various theories from the offline into the online world. This paper reviews all this theoretical evidence through focusing on two key elements. The first is the efficacy with which offline theories can explain behavior in the online world and the importance of new developments in the explanation of interpersonal relationships and communications in the online world. The second is the cultural specificity of specific theories and any research that has been produced to test them.
\end{abstract}

Keywords: Computer-Mediated Communication, Theories of Mating Relationships, Literature Review.

Cite this Article as: Ayman BAJNAID, Giuseppe Alessandro VELTRI, Tariq ELYAS and Ra'ed MASA'DEH (2019), "Computer-Mediated Communication Perspective on Theories of Mating Relationships: A Literature Review ", Journal of Internet Social Networking \& Virtual Communities, Vol. 2019 (2019), Article ID 432051, DOI: $10.5171 / 2019.432051$ 


\section{Introduction}

Researchers called for more research on the enabling factors of applying electronic services (e.g. Hunaiti et al., 2009; Shannak et al., 2010; Alkalha et al., 2012; Shannak et al., 2012; Masa'deh et al., 2013a,b; Obeidat et al., 2017; Tarhini et al., 2017; Masa'deh et al., 2019). Online dating provides a new setting and method for individuals to meet with potential partners for the first time, form impressions, and establish ongoing relationships. As the current overarching research objectives concerns mate preferences, impression formation, and the script of developing relationships between Saudis initiated through matrimonial websites, this paper reviews theories that investigate offline mate selection and their applicability to online dating sites, theories of offline and online impression formations, and online courtship models. The paper also evaluates the weaknesses and strengths of all the reviewed theories in relation to online environments.

Regarding the courtship theories, there are three approaches explaining courtship processes that are initiated online. The first approach bases its models on pre-existing offline relationship development theories and does not receive any support from either Western or Islamic scholars to test its applicability to courtship processes initiated online. The second approach generates new models through the utilisation of the grounded theory. Although this approach provides a description of the conditions that lead to the move from one stage to another, a detailed explanation of the users' behaviour and the interaction between users in each stage is missing. The third approach utilises script theory to provide a precise description of the stages of relationship development in an online context. This approach is characterised by being clear, accurate, and detailed. It describes the behaviour and conditions that lead to the transitioning from one stage to another. Indeed, it will be illustrated that the sexual strategy theory, hyper-personal theory and script theory offer an explanation for mate preferences strategies, impression formation, and courtship process that were initiated within Muslim matrimonial websites.

\section{Mate Selection Theories}

Scholars have investigated the criteria for selecting a partner in order to provide a better understanding of the process. Their approaches could be divided into three perspectives. The first perspective has focused on homogamy in personality traits, attitudes, and beliefs as the starting point in selecting a partner. The second perspective or the economic perspective has been adopted by scholars from different fields in their attempts to explain the mate selection process. The third perspective is the completion perspective. Some of the theories under these perspectives were not embraced in either offline or online mate selection studies, whereas others have only been studied offline, and the rest have been widely applied in both online and offline settings. This section provides an overview of the mate selection theories most relevant to the aims of the current research.

\section{The Homogamy Perspective}

Reiss (1960), Kerckhoff and Davis (1962), Lewis (1973), and Levinger (1983) based their theories on the homogamy perspective, that individuals are attracted to the company of people similar to themselves in characteristics such as race, social traits, and cultural background. That means that deep homogamy in values and beliefs should lead to successful partner selection. In particular, Kerckhoff and Davis (1962) illustrate this principle through their filter theory, based on the idea of illuminating heterogeneous traits through certain phases. Lewis' (1973) dyadic formation theory, Reiss's (1960) Wheel 
Theory of Love, and Levinger's (1983) "ABCDE" model echo this notion that homogamy enhances mutuality in certain circumstances that mainly depend on the partners' consensus in values and beliefs drawn from a shared culture, religion, and educational background. According to Määttä and Uusiautti (2013), in spite of the extensive body of mate selection research, there is insufficient support for these theories.

Hoyt and Hudson (1981) used another way to explain homogamy in mate selection by focusing on the similarities of personality traits. They collected a ranked list of preferred characteristics in a partner that revealed in previous research from 19391977. Based on their list, people had ranked "reliability" and "emotional balance" as significant. "Mutual attraction", "social character", and "education-intelligence" were characteristics that have increasingly become appreciated. "Decency" had become less important both in males' and females' lists, as had "good cooking and housekeeping skills" in males' preferences. However, Buss (1984) utilised three different methods (surveys, spouse rating, and interviews) to measure the correlation between married couples on 16 personal traits dimensions. Any of these traits has to be consistently demonstrated to be the aspect that governs partner choice, but the results revealed low correlations among them for all of these traits.

It is worth noting that the main strength of this perspective is that its main principle of similarity among partners has become an essential concept in some of the subsequent theories. The concept of homogamy is also in line with some of the traditional Saudi principals in mate selection. For instance, Saudi and Islamic cultures value the consensus between partners in their religion and beliefs. This principle is a must for women and favourable for men. However, the homogamy perspective might fail in providing a complete understanding of the mate selection process in an offline setting because it requires a direct interaction among partners. This interaction is necessary in order to determine or clarify their feelings toward each other and to decide together or individually to continue to the next stage, which is difficult to apply to Saudi culture in an offline setting. However, an online setting differs from an offline setting in some aspects. The former may provide individuals, especially those from a conservative background, more opportunities to know the extent of homogeneity between them and their potential partners in essential characteristics given their profile descriptions and screen names, and provide them the chance to interact directly with each other.

\section{The Economic Perspective}

Social exchange theory is the main branch of the economic perspective proposed by Thibaut and Kelley (1959) to explain the mate selection process through the calculation of the costs and rewards of the relationship. The authors have based their investment and equity model on the exchange of costs and rewards among couples, they emphasise that individuals try to maximize the rewards they get from the relationship as much as possible after subtracting their costs from it. These costs can be perceived as emotional, financial, or physical, and so forth (Allen, Babin, and McEwan, 2012). This process of coordination relies on two criteria when assessing the potential consequences of relationships. First, "the comparison level (CL)", which is the criterion against which an individual assesses the satisfaction of his \her relationship. Second, "the comparison level for alternatives (CLalt)", which is the criterion an individual depends on when assessing his \her interpersonal gains. Sprecher (2011) attempted to apply this theory to a longitudinal study among romantic partners to investigate the value of equity relative to social exchange factors (i.e., "rewards", "investments", and "alternatives") in expecting successful relationships. Consistent with the investment and equity Model, the study reveals that under- 
benefiting inequity was correlated with a greater likelihood of breakup.

Edwards (1969) proposes four interrelated assumptions regarding the procedure of mate selection that stem from social exchange theory: "the partner is selected by the rewards he or she brings into the relationship"; "individuals with equivalent resources are likely to maximize their rewards because they are likely to reject those with fewer resources"; "individuals with equivalent resources are likely to have equivalent characteristics", and "thus the relationship is likely to become homogenous". Edwards (1969) states that individuals with equal values do not have to be exactly the same in all positive characteristics because the balance is built on exchange theory, which is based on the equality between positive and negative features in several aspects. This assumption has been confirmed in a study conducted by Skopek, Schulz, and Blossfeld (2011). They collected data from an online German dating site $(\mathrm{n}=12,608)$ to investigate the significance of education in initiating and responding to online interactions. The findings indicate that educational homophily is the main determinate in online mating selection, as it significantly increases the likelihood of both starting and responding to online interactions. The findings also support social exchange theory's notion that homophily rises with educational qualification. While females are hesitant to contact a partner with lower educational level, males do not mind contacting less educated females.

Based on social exchange theory, the marriage market that determines costs and rewards differs from one culture to the next. For instance, a Russian study conducted by Sahib, Koning, and Witteloostuijn (2006) emphasizes being slim and proficient in English and living in a major city as important rewards sought in females in the Russian marriage market. Their study compares single Russian females who seek mates to females highlighted in a "Success
Stories" section among women living in cities and more rural areas $(n=575)$. The study finds that speaking English well and having a good body shape are positively correlated with success in the marriage market. Such a finding is in line with the assumption of social exchange theory that higher economic resources or the potential to live in a rich developed country could be exchanged for a good body shape and the capacity to speak English. Living in big cities also seems to be desirable. A Swedish study by Jakobsson and Lindholm (2014), on the other hand, reveals that being an Arab is considered a cost that would lower a person's value in the Swedish marriage market. The study applied social exchange theory to a number of Swedish online dating profiles $(n=1,490)$ to determine the significance of ethnicity (Swedish, Greek and Arab) in males' online dating preferences. The results reveal that being Swedish is highly evaluated in the dating market and that Arab daters face ethnic penalties in comparison with Swedes and Greeks. Such a result could be interpreted based on the idea that Arabs are ranked lower than Swedes in the Swedish social hierarchy, and thus going on a date with them could be interpreted as a cost.

Based on costs and rewards principles, Murstein (1970) proposed the concept of "premarital bargaining" in his stimulusvalue-role theory to account for the matching process commonly observed among real partners. It argues that physical attractiveness is viewed as a good that individuals invest in a dating market. In the early stages of courtship, individuals attempt to bargain with each other to obtain the most attractive partners possible in exchange for their personal physical attractiveness. Thus, individuals who are equal or similar in their physical attractiveness attempt to select each other. Murstein's matching hypothesis assumes the same outcome as anticipated by Walster, Aronson, Abrahams, and Rottman (1966) in their original matching hypothesis, which indicates that people who have similar levels of physical attractiveness are more 
likely to be attracted to select each other in the dating market.

Nevertheless, Murstein's theory is more inclusive than the initial matching hypothesis because his theory elaborately illustrates the circumstances under which having an attractive body is the main determinant of courtship desirability. This theory also clearly describes both behavioural and cognitive bases for the matching trend. The matching hypothesis indicates that in the dating market, each individual assesses his $\backslash$ her values and searches for a partner whose social desirability equals his \her own. Taylor, Fiore, Mendelsohn, and Cheshire (2011) conducted four studies to test this hypothesis, which implies that individuals' assessment of their own worth determines the partners they select. Their findings support that "self-worth", "physical attractiveness", and "popularity" predicts mating selection.

Although social exchange theories could be credited for being tested and amplified among different cultures in offline and online settings, they have been criticized because they largely equate relationships with a mechanical process that is free of emotions and reduced to purely mental and logical operations. Critics have argued that individuals differ in their level of repayment and the amount they spend in exchange. Also, people in general are not rational in their relationships and do not calculate their expected rewards, especially in long-term relationships (Stafford, 2008). Duck (1982) also argues that assessments of equity and exchange may happen in the first stages of a relationship and that individuals may not recognize inequalities or become disappointed about them until the relationship becomes disappointing. Some critics even go on to claim that social exchange theories cannot be considered theories at all, rather they are frames of reference within which many theoriessome micro and some macro-can support or oppose each other. Critics claim that many types of relationships cannot be explained through these theories (Stafford, 2008). Given that Saudi culture has different values compared to the Western world, it could be argued that investigating the criteria of the Saudi marriage market would yield different results.

\section{The Completion Perspective}

The completion perspective has been widely adopted by scholars to explain the process of mate selection. It is based on the fulfilment needs principle, in that people search for partners who complement them, fulfil their unfulfilled dreams, or resemble their ideal selves in order to obtain a productive relationship. For instance, in his instrumental theory, Centers (1975) argues that males and females have numerous needs that can supplement each other. Such an assumption differs from Winch's classic theory of complementary needs (1958) in stating that some needs are generally more important than others, and adding that sex and affiliation are more important than succour and abasement for both sexes when in love, and couples should show a significant positive correlation for both needs. Also, some needs are more important for one sex than another. In sum, theorists using the completion perspective examine partners' needs from several angles, such as social psychology (e.g., social role theory) or evolution (e.g., sexual strategies theory).

From the social psychological perspective, social role theory argues that males and females are attracted to traits in one another that are assets in a particular society (Eagly, Wood, and Diekman 2002). According to Whitty and Buchanan (2010), social role theory argues that males and females modify their behaviours to resemble gender roles valued by society. Thus, partnering with an attractive woman will raise a man's social status in Western society. On the contrary, as women often have fewer economic resources than men and they are expected to take care of children, women search for men with higher socio-economic statuses. Social role theory argues that when the structure of a 
society and the social categorization of males' and females' are different, both genders tend to seek mates who complement their characterises.

Whitty and Buchanan (2010) used this theory to investigate whether the screen names chosen by online daters provide advantages in attracting a mate on dating websites. The results reveal that males were more motivated to contact users with attractive screen names than females, while females were more motivated to contact users with neutral names or those whose screen names imply intelligence than males. These results could be interpreted as indicating that these individuals were attracted to qualities that might increase their social status in Western society. Hwang (2013) collected data from 2,123 online dating profiles from four self-reported racial groups (Asian, Black, Latino, and White) to test the applicability of this theory. Results have also indicated that willingness to date intra-racially was generally high and that willingness to date interracially was lower and influenced by racial social status. Because men evidenced an overall high willingness to date interracially, women's willingness to date outside their races provided a more accurate depiction of racial social status and exchange. Women of higher racial status groups were less willing than those from lower status groups to date interracially. Given the fact that the social roles of both sexes differ in Islamic societies compared to Western culture, it could be argued that cues of attractiveness may also differ, such as mentioning performing the five obligatory prayers daily, having a beard for men, and wearing a hijab for women; thus, applying social role theory to the Islamic context would yield different results.

From the evolutionary perspective, Darwin (1859) proposed that random changes in organisms' traits are more or less adaptive to survival in local environments. This perspective is based on the argument that when choosing a mate, individuals attempt to increase the genetic appropriateness of their descendants. They look for mates who have characteristics that enhance the existence of their offspring (Buss, 1989). Based on this notion, Buss and Schmitt (1993), in their sexual strategies theory, proposed that males and females developed distinctive strategies of their mate selections in long-term and short-term relationships. The strategies of males in long-term relationships are based on potential mates' characteristics that reflect their paternity confidence, reproductive value, commitment, good parenting skills and gene quality. On the contrary, the strategies of females in longterm relationships are based on potential mates' characteristics that reflect their ability to invest, willingness to invest, physical protection, commitment, good parenting skills and gene quality.

Although scientists across numerous disciplines like biologists, psychologists, sociologists, and anthropologists all argue that the physical attractiveness of a romantic mate is more important to men than it is to women (Gustavsson, Johnsson, and Uller, 2008; March and Bramwell, 2012), the view that males and females differ in their mate preferences has recently been challenged by research suggesting that physical attractiveness and economic status may be just as important to both sexes. Nevertheless, a recent meta-analysis study by Eastwick, Luchies, Finkel, and Hunt (2014) reveals no support for sex-differentiated desires and relational outcomes in either established relationships or mate selection contexts. As this meta-analysis study has been conducted among western samples, it may not be applicable to generalize its findings on the samples who belong to Islamic traditional cultures. Within these cultures, being responsible for expenses is considered among the main responsibilities of males, even if the females have high economic statuses. Nevertheless, sexual strategies theory provides one of the clearest articulations of both sexes' preferences for finding a partner for long-term relationships, such as marriage. Such articulations are important given that Saudi culture considers 
marriage the only acceptable framework for intimate relationships between sexes.

\section{Impression Formation Theories}

Online dating sites provide access to a considerable number of users' profiles, providing a basis for comparison. Unlike in an offline environment, impression formation starts in the online dating setting before the couple physically meets. Daters consider their profiles in online dating sites as résumés through which they constantly attempt to market their "best" selves (Heino, Ellison, and Gibbs, 2005). Therefore, individuals may spend a considerable amount of time forming attractive profiles that would leave a positive impression on their viewers. Aspects like screen name, profile photo, personal information, personal preferences, and description text are therefore heavily edited to provide the best impressions possible. In other words, users tend to put a lot of effort into creating flattering profiles (Whitty, 2010). This section provides an overview of the impression formation theories that are most relevant to the aims of the current research. In particular, it provides a review of offline impression formation theories and their applicability to online settings, the quality of impression formation in online settings from the perspective of computer-mediated communication theories, and impression formation management from individual and collective perspectives.

One of the early scholars to provide an explanation of impression formation in an offline setting is Goffman (1959). Goffman argues that the ways in which an individual engages with another is strategically manipulated "to convey an impression to others which it is in his interests to convey" (1959, p. 4). He outlines the basic tenets of this idea in his classic book, The Presentation of Self in Everyday Life. According to Goffman, individuals engage in performances to leave a positive impression on others. He also argues that to make positive impressions upon an audience, individuals try to emphasise their positive attributes and conceal any negative ones, thereby editing their self-presentation so as to be perceived in an acceptable way by the audience. Such altering of an individual's image depends mainly on the feedback and judgment received by the audience. Social norms are subsequently formed in the given social and cultural setting through feedback and judgments that help the individual to alter his or her image to be acceptable to others. Several studies have been conducted to determine the applicability of Goffman's (1959) impression formation theory in offline interaction contexts to the online dating context. They found that impression formation is often the first factor that plays a role in evaluating the success of the profile (e.g. Whitty, 2008; Ellison, Hancock, and Toma, 2011; Kalinowski and Matei, 2011).

In their investigation of the application of Goffman's theory in an online dating setting, Kalinowski and Matei (2011) not only explore the way individuals form impressions through their online profiles, but also whether they modify them according to the feedback of other users. They indicate that online profiles provide a space in which expectations regarding impression formation can be jointly structured. These expectations also support and enhance pre-existing rules within the online community. Further, social norms among users affect the types of behaviours that are considered acceptable. The study by Kalinowski and Matei (2011) revealed that the complex series of interactions among users were in fact governed by the social norms of the online context and the larger offline culture; further, they found that users' interactions influenced how they edited their profiles to form an impression. Although this theory provides substantial insight into impression formation in face-to-face contexts, it would appear to be incomplete with regard to such formation in a computer-mediated context. This is because impression formation in a mediated context occurs through written communication without the visual cues present in face-to-face contexts. 
Computer-mediated communication theorists have explored the quality of impression formation in online settings and hold different perspectives. While some scholars argue that it is difficult to form an impression online due to the impersonality of messages (Short, Williams and Christie, 1976; Sproull and Kiesler, 1986), some indicate that it reduces self-definition based on the identity of one's social group (Spears and Lea, 1992; 1994; Reicher, Spears and Postmes, 1995; Postmes, Spears and Lea, 1998). The rest argue that an online setting has an advantage over an offline setting in that it enables users to control the impressions they create online (Walther, 1996; McKenna, 1998; McKenna, Green, and Gleason, 2002; Whitty, 2008, 2010).

Early scholars in the field of computermediated communication argue that impression formation is limited in an online setting because the lack of social cues forms impersonal messages between users. For instance, Short, Williams, and Christie (1976) argue in their social presence theory that the fewer the channels or codes offered by a medium, the less energy users devote to the existence of other social members in a communication. On a continuum of social presence, the offline medium is viewed as having the most social presence and online communication the least. In addition, Sproull and Kiesler (1986) argue that computermediated communication decreases "social context cues" - features of physical setting, charisma, and nonverbal ordered status cues-the absence of which is considered to prevent interpersonal formation of impressions. Culnan and Markus (1987) called these kinds of approaches the "cuesfiltered-out" perspective. Although this perspective received support at that time, it did not last long.

Taking a group perspective as their standpoint, Spears and Lea (1992; 1994) and Reicher, Spears, and Postmes (1995) were the first to empirically discover the practical element of group behaviour roles in forming impressions online. Their social identity model of deindividuation effects (SIDE) was originally proposed to provide an explanation of deindividuation effects that emerged from situational aspects like "group immersion", "anonymity", and "reduced identifiability". They argue that deindividuation manipulations can impact an individual's capability to express identityrelevant behaviour once an identity is prominent. Individuals in computermediated communication viewed themselves as part of a predominant social group, and that anonymity can enhance the prevalence of shared social identity instead of individual identity. When writers have a shared social identity, they are more inclined to "group influence", "social attraction", "stereotyping", "gender typing", and "discrimination" in online interaction conducted anonymously (Postmes, Spears, and Lea, 1998). This model distinguishes between two kinds of anonymity in online interaction: anonymity of others to the users and anonymity of the users to others, which is referred to as "identifiability". Although the social identity model of deindividuation impact is in line with collective culture in some of its assumptions, it fails to highlight the role that individual differences may play in forming a positive impression online.

A study by Tanis and Postmes (2003) revealed that social cues affect two characteristics of impression formation: "ambiguity" and "positivity of impressions". These social signs, which can be as limited as a photograph or some biographical background information, significantly impact impression formation. The findings reveal that the disappearance of social cues is correlated with less positive impressions than the presence of one or both. Thus, different from what was expected on the basis of the social identity model of deindividuation effects, group membership does not impact the relationship between social cues and positivity of impression.

On the other hand, Walther (1992, 1993, 1996), in his social information processing (SIP) theory and then hyperpersonal theory, 
indicated that due to these lack of social cues, users could be quite strategic in lessening potential partners' access to their undesirable attributes because they can design, construct, and manage their impression formation much more intentionally than they would in face-to-face first meetings. This notion has been applied in several studies (e.g., Tidwell and Walther, 2002; Walther, 2007). It has also been confirmed by Vasalou and Joinson (2009) research on self-presentation through online avatars; their results revealed that participants in the online dating setting emphasised specific aspects of their avatar in order to present a more attractive self. Walther's hyperpersonal theory (1996) helps in demonstrating the communication components of sender, receiver, channel, and feedback in online environment. It also explains how impressions are formed and relationships are initiated and developed. The weakest point of hyperpersonal theory is that it does not investigate whether its numerous assumptions are theoretically interdependent or simply accidental (Walther and Parks, 2002).

When comparing impression formation between offline and online settings among conservative Saudi Islamic cultures, it can be said that the offline setting is the one that lacks social cues between the sexes. Due to the hijab, Saudi women are obliged to cover their whole bodies, and the majority of women cover their faces as well. This means that males will not be able to easily form an impression due to the lack of both verbal and non-verbal social cues from females. Thus, it could be argued that for Saudis, an online setting would carry more information than face-to-face meetings, as an online environment would enable users to experience a more intensive interaction in comparison to face-to-face meetings. Given that there is a lack of research regarding online interactions among Saudis, addressing the impact of social cues in online settings will contribute to the body of knowledge.

\section{Theories of the Courtship Process Initiated Online}

The emergence of developing relationships in cyberspace has drawn the attention of computer-mediated communication scholars to investigating the stages that partners go through when developing their relationships online. There are three approaches explaining courtship processes that were initiated online. The first approach based its models on pre-existing offline relationship development theories (e.g. Sprecher, 2009; Whitty, 2010). The second generated new models through the utilisation of grounded theory (e.g. LaBuda, 2012). The third depends on script theory to provide a precise description of the stages of relationship development in an online context (e.g. Long, 2010). This section provides an overview of these approaches, their strength and weaknesses, and their applicability to the Saudi script of courtship processes initiated in matrimonial websites.

In explaining the initial stages of courtship grounded in offline theories, Sprecher (2009) based her model on Levinger's (1974) three stages of relationship initiation. The first stage is awareness of the other. This stage occurs online when an individual accesses the profile of the potential partner, visits his/her blog or profile, or sends him/her an online message. The second stage, the surface contact stage, starts when online users contact others after they have received a great deal of information about the other from his/her profile, his/her interaction with others and his/her posts, activities and preferences. According to Sprecher (2009), although the first two stages are considered important to forming an online relationship, a "real relationship" cannot be considered to exist unless there is "mutuality" and "interdependence" between the two partners, which is considered the third stage. Characteristics of this final stage are "interdependence", "self-disclosure", "investment in each other", and "a feeling of couple identity". Sprecher (2009) argues that in order to reach full mutuality, an offline 
contact requires the couples to reach the "mutuality" and "interdependence" levels. However, this model of relationship development is more descriptive than explanatory. It also does not cover when the change in a stage happens and when transitions from one stage to another occur. What is the stimulus for the transfer from one stage to another? What are the situations surrounding that transfer? What are the situations surrounding the transfer that is not identified? In short, Sprecher (2009) relationship development model falls short in terms of theoretical clarity and specificity. It does not receive any support from either Western or Islamic scholars to test its applicability to courtship processes initiated online.

A more sophisticated model that is also based on an offline theory is articulated by Whitty (2010), who based her developing relationships model of online dating sites on Givens' (1979) five-stage theory of the traditional courting process. In stage one (the attention stage), an individual starts trying to catch the attention and attraction of a potential partner by sending non-verbal cues. In online dating, an individual does not have a specific target towards whom to show interest. Therefore, the individual sends attention signals through maintaining an attractive profile and posting a personal photo to introduce himself/herself. Whitty (2007) suggests in her BAR approach that online daters should maintain a balance between their attractiveness and real selves when constructing their online profiles. An ideal presentation of the self does not work in the context of online dating sites: if people do not live up to their profiles, they typically do not earn a second date. Presenting a real profile also means avoiding writing anything that appears too clichéd. The second stage (the recognition stage) requires more flirting. In this stage, users replace exchanging emails between the members of the site with sending "pokes" or "kisses", which seems less intrusive than sending a direct email to express interest in a member and disclose information to this member. Stage three (the interaction stage) begins with exchanging emails through the site and often evolves into the exchange of cell phone numbers and text messages. The face-to-face meeting stage, the fourth stage, is very important in determining whether the two individuals will have further dates or not. However, this stage is different from traditional dates because the sexual attraction had already begun online. The purpose of the meeting for the online daters is to test the chemistry between them and the similarities and differences between them and their profiles. The last stage (resolution) occurs when an individual decides after the first date if he/she is sexually attracted to the other person, and then decides whether to go on another date with that person or go back to the dating website to search for other options. Despite its clarity, accuracy, and detail, Whitty's (2010) theory only addresses the development of relationships via online dating websites in Western society, which is totally different from the Islamic culture. The weakest point in this approach, which based its models on offline theories, is that there are no offline theories that could explain Islamic offline courtship processes that could be in turn applied to online settings.

LaBuda (2012) has put forward an online relationship model utilising the grounded theory. His model consists of four distinctive stages: He argues that an online relationship starts when the participants have a desire to find a significant other and they believe that there is no other way to meet them, which leads them to put their profiles on an online dating site. Second, users start to enjoy the control that the online dating site provides them. The third stage states that being open to a new experience leads to a successful relationship development. Finally, the personality trait to take a risk in moving the relationship offline determines whether it will flourish or fail. Although this model provides a description of the conditions that lead to the move from one stage to another, a detailed explanation of the users' behavior and the interaction between users in each stage is missing. 
Utilising script theory, Long (2010) provided a model to explore the processes and scripts for online relationships initiated in dating websites. Long's model consists of 14 stages. These stages are as follows: (A) Love styles: date seekers usually explained that they do not have only one way to relate to others romantically, but rather that they have a mix of styles or "want it all." (B) Deciding to join an online dating site: given a lack of partners offline, their acquaintances had had more success dating online. They want to find a partner or date, and since it is more efficient than initiating dates offline, they decide to join the site. (C) Goals for online dating: individuals use sites for their own purposes, whether for a serious partner, casual dates, or fun. (D) Choosing a dating site: date seekers choose a site based on the perceived members of the site, the culture and features of the site (including cost), their goals for online dating, and how they perceive the site's ability to help them achieve those goals. Daters may join more than one site. (E) Creating a profile: date seekers must create a profile and describe what or who they are looking for in terms of a partner. (F) Matching: users are provided with potentially compatible partners through a list or searching feature. (G) Making decisions about matches: once a list of potential matches or results of a search is available, users make decisions about matches. If the matches are turned down, contact is stopped. $(\mathrm{H})$ The process returns to the matching step (F). (I) Initial contact with matches can take place before and/or after the decisions about the matching step $(\mathrm{G})$. (J) If both parties pass the tests, this establishes a mutual match. A mutual match means that both date seekers want to advance their communication. (K) Engaging in mediated communication: depending on their levels of interest and additional rounds of elimination, the match can move to phone calls and text messages or skip right to meeting offline. (L) Meeting face-to-face: the date seekers discuss moving the relationship offline and meeting in person, as well as discussing when/where/how to meet. If the decision to continue offline contact is made by both parties, (M), it stays offline and the match no longer uses the dating site $(\mathrm{N})$. This model is characterized by being clear, accurate, and detailed. It describes the behavior and conditions that lead to transitioning from one stage to another. Using script theory as a theoretical framework would provide a more comprehensive and systematic model as it enables the researchers to capture users' actions and the decisions behind them. Being based on Western culture, it would be interesting to know which stages provided by this script model would match the script provided by Saudis regarding their courtship process initiated through matrimonial websites.

\section{Conclusion}

This study reviewed the theories relevant to the understanding of online dating. Reviewing the theories of mate preferences shows that these theories fall within three perspectives: homogamy perspective, economic perspective, and completion perspective. While the main strength of the homogamy perspective is that its main principle of similarity among partners has become an essential concept in some of the subsequent theories, there is insufficient support for homogamy perspective in the empirical research. The theories under the economic perspective could be credited for introducing new concepts such as "marriage market", "premarital margining", "selfworth", and "costs and rewards". Nevertheless, these theories have been criticized because they equate relationships with mechanical processes that are free of emotions and reduced them to purely mental and logical operations. Some critics have even claimed that the economic theories cannot be considered theories at all, rather they are frames of reference within which many theories can support or oppose each other. The completion perspective has, on the other hand, been widely adopted by scholars to explain the process of mate selection. In particular, sexual strategies theory provides one of the clearest articulations of both sexes' preferences for finding a partner for long- 
term relationships, such as marriage. Such articulations are important given that Saudi culture considers marriage the only acceptable framework for intimate relationships between sexes.

Focusing on impression formation theories, while Goffman's (1959) self-presentation theory provides a substantial insight into impression formation in face-to-face contexts, it appears to offer an incomplete explanation to such formation in the usage of matrimonial websites' context. Although the social identity model of deindividuation is applied in the online context and it is in line to some extent with the nature of collective culture, it fails to highlight the role that individual differences may play in forming a positive impression online. On the other hand, Walther's hyperpersonal theory (1996) helps in demonstrating the communication components of sender, receiver, channel, and feedback in online environment. It also explains how impressions are formed and relationships are initiated and developed online.

\section{References}

1. Alkalha, Z., Al-Zu'bi, Z., Al-Dmour, H., \& Alshurideh, M. (2012). Investigating the effects of human resource policies on organizational performance: An empirical study on commercial banks operating in Jordan. European Journal of Economics, Finance and Administrative Sciences, 51, 4464.

2. Allen, L.F., Babin, E.A., \& McEwan, B. (2012). Emotional investment: An exploration of young adult friends' emotional experience and expression using an investment model framework.Journal of Social and Personal Relationships, 29(2), 206227.

3. Buss, D. \& Schmitt, D. (1993). Sexual strategies theory: An evolutionary perspective on human mating. Psychological Review, 100, 204-232.

4. Buss, D.M. (1984). Marital assortment for personality dispositions:
Assessment with three different data sources. Behavior genetics, 14(2), 111-123.

5. Buss, D.M. (1989). Sex differences in human mate preferences: Evolutionary hypotheses tested in 37 cultures. Behavioral and Brain Sciences, 12(01), 1-14.

6. Centers, R. (1975). Sexual attraction and love: An instrumental theory. Springfield, IL: Thomas Pub Ltd.

7. Culnan, M.J., \& Markus, M.L. (1987). Information technologies. In F. M. Jablin, L.L. Putnam, K.H. Roberts, \& L.W. Porter (Eds.), Handbook of organizational communication: An interdisciplinary perspective (pp. 420443). Newbury Park, CA: Sage.

8. Darwin, C. (1859). On the origin of species by means of natural selection. London: Murray.

9. Duck, S. (1982). A topography of relationship disengagement and dissolution. Personal relationships, 4, 1-30.

10. Eagly, A., Wood, W., Diekman, A. (2002). Social role theory of sex differences and

similarities: A current appraisal. In T. Eckes \& HM Trautner (Eds.), The developmental social psychology of gender (pp. 123-174). Mahwah, NJ: Erlbaum.

11. Eastwick, P.W., Luchies, L.B., Finkel, E.J., \& Hunt, L.L. (2014). The many voices of Darwin's descendants: Reply to Schmitt.Psychological Bulletin, 140(3), 673681.

12. Edwards, J.N. (1969). Familial behavior as social exchange. Journal of Marriage and the Family, 518-526.

13. Ellison, N., Hancock, J., \& Toma, C. (2011). Profile as promise: A framework for conceptualizing veracity in online dating selfpresentations. New Media and Society, 13(6), $1-18$.

14. Givens, D. (1979). The non-verbal basis of attraction: Flirtation, courtship, and seduction. Psychiatry, 41, 346-359.

15. Goffman, E. (1959). The presentation of self in everyday life. New York, NY: Anchor.

16. Gustavsson, L., Johnsson, J.I., \& Uller, T. (2008). Mixed support for sexual selection theories of mate preferences in the Swedish population. Evolutionary Psychology, 6(4), 575-585. 
17. Heino, R.D., Ellison, N.B., \& Gibbs, J.L. (2005). Are we a "match"? Choosing partners in the online dating market. Paper presented at the meeting of the International Communication Association, New York.

18. Hoyt, L.L., \& Hudson, J.W. (1981). Personal characteristics important in mate preference among college students. Social Behavior and Personality: An International Journal, 9(1), 93-96.

19. Hunaiti, Z., Mansour, M., \& AlNawafleh, A. (2009). Electronic commerce adoption barriers in small and medium-sized enterprises (SMEs) in developing countries: The case of libya. Innovation and Knowledge Management in Twin Track Economies Challenges and Solutions-Proceedings of the 11th International Business Information Management Association Conference, IBIMA 2009, 1-3, 1375-1383.

20. Hwang, W.C. (2013). Who are people willing to date? Ethnic and gender patterns in online dating. Race and Social Problems, 5(1), 28-40.

21. Jakobsson, N., \& Lindholm, H. (2014). Ethnic preferences in internet dating: A field experiment. Marriage \& Family Review, 50(4), 307-317.

22. Kalinowski, C., \& Matei, S. (2011). Goffman meets online dating: Exploring the 'virtually' socially produced self. Journal of Social Informatics, 16, 6-20.

23. Kerckhoff, A.C., \& Davis, K.E. (1962). Value consensus and need complementarity in mate selection. American Sociological Review, 295-303.

24. LaBuda, M. (2012). Individuals involved in online dating sites description of the process of developing a relationship: $A$ grounded theory study. Unpublished $\mathrm{PhD}$ dissertation. Capella University.

25. Levinger, G. (1974). A three-level approach to attraction: Toward an understanding of pair relatedness. In T.L. Huston (Ed.), Foundations of interpersonal attraction (pp. 99-120). New York: Academic Press.

26. Levinger, G. (1983). Development and change. In H.H. Kelley, E. Berscheid, A Christensen, IH. Harvey, T.L. Huston, G. Levinger, E. McClintock, LA Peplau, \& D.R
Peterson (Eds.), Close relationships (pp. 315359). New York, NY: Freeman.

27. Lewis, R.A. (1973). Social reaction and the formation of dyads: An interactionist approach to mate selection. Sociometry, 409418.

28. Long, B.L. (2010). Scripts for online dating: A model and theory of online romantic relationship initiation. Unpublished Doctoral dissertation. Bowling Green, OH: Bowling Green State University.

29. Määttä, K., \& Uusiautti, S. (2013). Who is the one? The difficulty in selecting the partner. In K. Määttä, \& S. Uusiautti (Eds.), Many Faces of Love (pp. 19-39). Rotterdam, The Netherland: The Sense Publishers.

30. March, E., \& Bramwell, A. (2012). Sex Differences in mate preferences in Australia: Exploring evolutionary and social-economic Theories. Journal of Relationships Research, 3, 18-23.

31. Masa'deh, R., Almajali, D., Alrowwad, A., \& Obeidat, B. (2019). The role of knowledge management infrastructure in enhancing job satisfaction: A developing country perspective. Interdisciplinary Journal of Information, Knowledge \& Management, 14, $1-25$.

32. Masa'deh, R., Gharaibeh, A., Maqableh, M., \& Karajeh, H. (2013a). An empirical study of antecedents and outcomes of knowledge sharing capability in Jordanian telecommunication firms: A structural equation modeling approach. Life Science Journal, 10 (4), 2284-2296.

33. Masa'deh, R., Shannak, R., \& Maqableh, M. (2013b). A structural equation modeling approach for determining antecedents and outcomes of students' attitude toward mobile commerce adoption. Life Science Journal, 10 (4), 2321-2333.

34. McKenna, K.Y.A. (1998). The computers that bind: Relationship formation on the Internet. Unpublished $\mathrm{PhD}$ dissertation. Athens, $\mathrm{OH}$ : Ohio University. 35. McKenna, K.Y.A., Green, A.S., \& Gleason, M.E.J. (2002). Relationship formation on the Internet: What's the big 
attraction? Journal of Social Issues, 58(1), 931.

36. Murstein, B.I. (1970). Stimulus value role: A theory of marital choice. Journal of Marriage and the Family, 465-481.

37. Obeidat, B., Tarhini, A., \& Aqqad, N. (2017). The impact of intellectual capital on innovation via the mediating role of knowledge management: A structural equation modeling approach. International Journal of Knowledge Management Studies, 8 (3-4), 273-298.

38. Postmes, T., Spears, R., \& Lea, M. (1998). Breaching or building social boundaries? SIDE- effects of computermediated communication. Communication Research, 25(6), 689-715.

39. Reicher, S.D., Spears, R., \& Postmes, T. (1995). A social identity model of deindividuation phenomena. European Review of Social Psychology, 6, 161-198.

40. Reiss, I.L. (1960). Toward a sociology of the heterosexual love relationship. Marriage and Family Living, 139-145.

41. Sahib, P.R., Koning, R.H., \& van Witteloostuijn, A. (2006). Putting your best cyber identity forward an analysis of 'success stories' from a Russian internet marriage agency. International Sociology, 21(1), 61-82.

42. Shannak, R., Al-Zu'bi, Z., Obeidat, B., Alshurideh, M., \& Altamony, H. (2012). A theoretical perspective on the relationship between knowledge management systems, customer knowledge management, and firm competitive advantage. European Journal of Social Sciences, 32 (4), 520-532.

43. Shannak, R., Obeidat, B., \& Almajali, D. (2010). Information technology investments: A literature review. Business Transformation through Innovation and Knowledge Management: An Academic Perspective-Proceedings of the 14th International Business Information Management Association Conference, IBIMA 2010, 1356-1368.

44. Short, J., Williams, E., \& Christie, B. (1976). The social psychology of telecommunications. London: Wiley Publishing. 45. Skopek, J., Schulz, F., \& Blossfeld, H.P. (2011). Who contacts whom? Educational homophily in online mate selection. European Sociological Review, 27(2), 180-195.

46. Spears, R., \& Lea, M. (1992). Social influence and the influence of the "social" in computer-mediated communication. In M. Lea (Ed.), Contexts of computer-mediated communication (pp. 30-65). London: HarvesterWheat-sheaf Publishing.

47. Spears, R, \& Lea, M. (1994). Panacea or panopticon? The hidden power in computermediated communication. Communication Research, 21,427459 .

48. Sprecher, S. (2009). Relationship initiation and formation on the Internet. Marriage \& Family Review, 45(6-8), 761-782.

49. Sprecher, S. (2011). The influence of social networks on romantic relationships: Through the lens of the social network. Personal Relationships, 18(4), 630-644.

50. Sproull, L., \& Kiesler, S. (1986). Reducing social context cues: Electronic mail in organizational communication. Management Science, 32(11), 1492-1512.

51. Stafford, L. (2008). Social exchange theories. Engaging theories in interpersonal communication: Multiple perspectives, 377389.

52. Tanis, M., \& Postmes, T. (2003). Social cues and impression formation in CMC. Journal of Communication, 53, 676-693.

53. Tarhini, A., Al-Badi, A., Almajali, M., \& Alrabayaah, S. (2017). Factors influencing employees' intention to use cloud computing. Journal of Management and Strategy, 8(2), 47.

54. Taylor, L.S., Fiore, A.T., Mendelsohn, G.A., \& Cheshire, C. (2011). "Out of my league": A real-world test of the matching hypothesis. Personality and Social Psychology Bulletin, 37(7), 942-954.

55. Thibaut, J.W., \& Kelley, H.H. (1959). The social psychology of groups. New York, NY: Wiley.

56. Tidwell, L.C., \& Walther, J.B. (2002). Computer-mediated communication effects on disclosure, impressions, and interpersonal evaluations: Getting to know one another a bit at a time. Human Communication Research, 28(3), 317-348. 
57. Vasalou, A., \& Joinson, A. (2009). Me, myself and I: The role of interactional context on self-presentation through Avatars. Computers in Human Behavior, 25, 510-520.

58. Walster, E., Aronson, V., Abrahams, D., \& Rottman, L. (1966). Importance of physical attractiveness in dating behavior. Journal of personality and social psychology, 4(5), 508-516.

59. Walther, J.B. (1992). A longitudinal experiment on relational tone in computermediated and face to face interaction. Proceedings of the Hawaii International Conference on System Sciences, 4, 220-231.

60. Walther, J.B. (1993). Impression development in computer-mediated interaction. Western Journal of Communication, 57, 381-398.

61. Walther, J.B. (1996). Computermediated communication: Impersonal, interpersonal, and hyperpersonal interaction. Communication Research, 23, 343.

62. Walther, J.B. (2007). Selective selfpresentation in computer-mediated communication: Hyperpersonal dimensions of technology, language, and cognition. Computers in Human Behavior, 23(5), 2538-2557.
63. Walther, J.B., \& Parks, M.R. (2002). Cues filtered out, cues filtered in: Computermediated communication and relationships. Handbook of interpersonal communication, 3, 529-563.

64. Whitty, M. (2007). The art of selling one's self on an online dating site: The BAR approach. Online Matchmaking, 57-69.

65. Whitty, M. (2008). Revealing the "real" me, searching for the "actual" you: Presentations of self on an internet dating site. Computers in Human Behavior, 24, 17071723.

66. Whitty, M. (2010). E-Dating: The five phases on online dating. In C. RommLivermore and K. Setzekorn (Eds.). Social networking communities and e-dating services: Concepts and implications (pp. 278291). Hershey, PA: IGI Global Publishing.

67. Whitty, M., \& Buchanan, T. (2010). What's in a screen name? Attractiveness of different types of screen names used by online daters. International Journal of Internet Science, 5(1), 5-19.

68. Winch, R.F. (1958). Mate selection: A theory of complementary needs. New York: Harper. 